\title{
Una lectura hipermoderna de La risa de Henri Bergson. De la risa como pequeño enigma malicioso a su comprensión como ethos de las sociedades
}

\author{
Salvador Solis Castro \\ Universidad Veracruzana
}

Resumen: En el presente ensayo se analizan algunos aspectos importantes de la interpretación elaborada por Henri Bergson acerca de "la risa" y el fenómeno de lo cómico en relación, principalmente, a lo social. Este aspecto, crucial a nuestro juicio, es lo que nos permite pensar dicho fenómeno más allá de la pura frontera estética, hacia los linderos siempre dificiles del ethos. Tomando en cuenta también la relación entre esta propuesta y otros aspectos del llamado "bergsonismo", en lo que sigue afirmamos y defendemos el potencial correctivo y ético de la risa dentro de la generalidad de su filosofia.

Palabras clave: risa; comicidad; ethos; sociedad; mecanicidad; rigidez

Abstract: "A Hypermodern Reading of Laughter by Henri Bergson. From Laughter as a Malicious Little Enigma to its Understanding as an ethos of Societies". In this essay, we analyze some important aspects of the interpretation elaborated by Henri Bergson regarding "laughter" and the phenomenon of the comical, especially in its relation to the social. This aspect, crucial in our opinion, is what allows us to think about this phenomenon beyond the pure aesthetic frontier, and towards the always-difficult boundaries of the ethos. Also taking into account the connection between this proposal and other aspects of the so-called "bergsonism", in what follows we affirm and defend the corrective and ethical potential of laughter within the generality of its philosophy.

Keywords: laughter; comicality; ethos; society; mechanical philosophy; rigidity 
"Chispea como la espuma del licor. Es alegría. Pero el filósofo que la recoge para saborearla, encontrará algunas veces por una exigua cantidad de materia, una cierta dosis de amargura" Henri Bergson

"I find that a duck's opinion of me is very much influenced over whether or not I have bread" Mitchell Lee Hedberg

\section{La risa en movimiento}

¿Por qué la risa no es tan socorrida por los estudiosos? ¿Será acaso que, como bien apunta Bergson, la risa es aquella espuma que se nos escapa de las manos cuando intentamos aprehenderla? No obstante, aunque sea por un momento intentemos delinear los contornos de dicha espuma. En el presente ensayo nos proponemos básicamente tres tareas: comprender los movimientos del fenómeno de la risa en Bergson, acercarnos al fenómeno de la risa desde Bergson (pero también más allá de él) y legitimar la risa como un pequeño enigma malicioso.

Alejándonos de Yankelevitch ${ }^{1}$, pensamos que entre 1896 y 1903, es decir, entre las publicaciones de Materia y memoria y de la Introducción a la metafisica, encontramos una de las obras claves del pensamiento de Henri Bergson. Si bien es cierto que esta última se encuentra todavía inmersa en las aguas de un psicologismo más bien cuestionable, y si bien es unánime que la segunda resulta una de las publicaciones más polémicas de la filosofía francesa, lo es también que, en diversos sentidos, ambas se encuentran impregnadas de los movimientos éticos y metodológicos de La risa.

236 Negar la incidencia de los nueve principios metafísicos establecidos por Bergson en su texto de 1903 en el desarrollo de las corrientes más importantes del pensamiento posmoderno sería absurdo. Es precisamente en el contexto de esta sólida recepción, que La risa emerge como la actitud por antonomasia

1 Yankelevitch, V., Henri Bergson, Xalapa: Universidad Veracruzana, 2006. 
contra el positivismo desde el positivismo en cuanto tal. Es decir, emerge como cristalización del precepto vitalista de subsumir para superar ${ }^{2}$. Posiblemente, de entre la vasta obra de Bergson, La risa sea el ejemplo más claro de esta superación por medio de la asimilación, pues no se trata de una simple fusión entre psicología y biología, sino más bien de un "profundo" acercamiento intuitivo a un acontecer que es más nouménico que fenoménico: justamente, la risa ${ }^{3}$.

Para modelar mejor el papel de esta obra en el interior de la obra bergsoniana, vale traer a la escritura el recuerdo de su gran compatriota Alfred de Musset. Si bien es cierto que las diferencias entre la Francia de 1800 y la Francia de 1900 son notorias, estos dos autores están hermanados por una sinceridad y compromiso con el siglo por venir. En este sentido afirmamos que La risa de Bergson es el análogo paralelo de las Confesiones de un hijo del siglo de Musset, sin riesgo de caer en fundamentos gnósticos y simplemente evocando el parentesco a modo de preámbulo.

Empecemos, pues, por el verbo latino ridere y su participio risus. Como bien apunta Moliner, podemos subrayar fenoménicamente que el acto de "contraer ciertos músculos de la cara que estiran los labios dejando a la vista los dientes y dando una expresión particular a los ojos"4 denota y connota lo que aquí hemos de designar como "risa". Pero, ¿es esto suficiente? No, porque la respuesta legada por el propio Bergson nos dice que una definición como la citada implicaría necesariamente que otros mamíferos participan de la risa, lo cual, como intentará mostrarnos, es absolutamente falso. En esto consiste la distinción metodológica inicial: la risa en un primer momento escapa a los contornos fisiológicos-filológicos porque los atraviesa y los excede. Esta es la razón por la cual Bergson solo puede acercarse a ella a la luz de tres grandes conjuntos o ejes de reflexión: lo cómico en general, lo cómico de las formas y lo cómico de los movimientos. Esto se puede traducir respectivamente como la fuerza expansiva de lo cómico, lo cómico como situación y lo cómico como acto verbal (esto es, lo cómico de los caracteres).

\footnotetext{
2 Véase para la relación entre el análisis bergsoniano de la risa y su relación con diversas formas de vitalismo filosófico, Cherniavsky, A., "La risa como práctica formativa vitalista. La función y el valor de la risa en Spinoza, Nietzsche, Bergson y Deleuze", en: Configuraciones formativas II, 2 (2007).

3 Recordemos en este punto las palabras de Deleuze en relación al modo preciso en que la "intuición" ha de entenderse en los marcos de la metodología de Bergson: "La intuición no es un sentimiento ni una inspiración, no es tampoco una simpatía confusa, sino un método elaborado, incluso uno de los métodos más elaborados de la filosofia" (Deleuze, G., El bergsonismo, Madrid: Cátedra, 1987, p. 9).

4 Moliner, M., Diccionario de uso del español, v. I, Madrid: Gredos, 1998, p. 1045.
} 
No es secreta la profunda pasión que Bergson sentía por el arte en general $y$, específicamente, por el teatro. No es extraño que uno de los primeros eslabones de análisis utilizados durante el desarrollo del estudio sea la oposición entre aquello que, grosso modo, se denomina bajo el ámbito de lo cómico y aquello que al contrario se identifica con lo trágico. Este es el tono general del capítulo segundo de La risa en el que abundan ejemplos y referencias teatrales. Pese a su innegable importancia y tomándose en cuenta simples criterios de precisión y claridad, habremos de dejarlo de lado y atenernos con puntualidad a los capítulos primero y tercero.

Ahora bien, el principal interés de Bergson al abordar el asunto de la risa puede subsumirse en lo que de ahora en adelante denominaremos ethos del humor. A la par, las reglas de su juego, modestamente profundas en resonancia con el espíritu de las Confesiones de Musset, aparecen contenidas en su generalidad en el siguiente pasaje: "Digámoslo desde ahora: solo en este sentido se puede afirmar que la risa castiga las costumbres, haciendo que nos esforcemos por parecer lo que debíamos ser, lo que indudablemente llegaremos a ser algún día"5. Estas son, digámoslo llanamente, las cartas sobre la mesa: el acercamiento hacia la risa no será de cualquier tipo, ni pertenecerá a cualquier dominio del pensamiento. Por el contrario, estará en constante tensión respecto de lo social. Sus giros, contornos, formas y movimientos se encontrarán en este.

Veamos. La primera categoria que podemos aplicar al acontecer de la risa en tanto fenómeno sustantivado por una sociedad es la de tensión/ elasticidad. Veamos en qué sentido las relaciones que se generan entre los miembros de una comunidad dada generan un tipo de devenir ético "natural"6 que Bergson interpreta como una suerte de telos inmanente a lo social per se. Esta finalidad, a la que se encuentran supeditados todos sus miembros, no debe confundirse en ningún momento con ninguna clase de dirección ideológica, sino más bien, en sentido fuerte, ha de entenderse como una tendencia "vital" del ser-con-otro hacia la perfección. Tampoco debemos pensar que este impulso compartido, este "actuar", es equivalente a una "decisión" compartida. Se trata en cambio de un acto de la "vida misma", del impulso de la vida que excede al individuo: "Tensión y elasticidad, he aquí dos fuerzas complementarias que hacen actuar a la vida"7. Con estas palabras, Bergson deja establecido que el élan vital no

\footnotetext{
5 Bergson, H., La risa: ensayo sobre la significación de lo cómico, Madrid: Orbis, 1986, p. 20.

6 Cabe subrayar que dicha naturalidad resulta, al interior del pensamiento bergsoniano, más artificial de lo que él imagina, dada la complejidad de las redes sociales industrializadas.

7 Bergson, H., La risa: ensayo sobre la significación de lo cómico, p. 21.
} 
es una voluntad-de-vivir a la Dussel (con toda proporción guardada), sino un alejamiento radical de cualquier teoría sobre la vida que pudiera acercarse al darwinismo. El azar en la vida no determina la adaptación, sino que, por todo lo opuesto, la vida misma es la que regula el acaecer de su telos. Vale la pena evocar en este punto la idea de "evolución creadora" tal y como es expuesta en el texto homónimo de 1907, es decir, en tanto guía reguladora de este movimiento. Esto nos lleva a plantear el segundo principio básico de la metafísica de Bergson, a saber, el llamado "estado-naciente", la ontología del movimiento en toda espectacularidad. El movimiento, precisamente, como eso que la "evolución creadora" representa: la cancelación ontológica de lo inmóvil; absolutamente8.

Ahora bien, si el fenómeno social está inmerso en esta ontología del movimiento, surgen al menos las siguientes preguntas: ¿Hacia dónde va? ¿Qué regula el movimiento de lo social en su conjunto? Aunque puramente negativa, la estrategia brindada por Bergson es radical: la única forma de dar respuesta a estas cuestiones será, precisamente, indagando sobre la risa, pues ella, entre todos los fenómenos, es la que tiene la capacidad de mostrarnos qué camino no ha de seguir ese telos.

El que la rigidez sea una posible manifestación de la inmovilidad ${ }^{9}$ explica por qué para Bergson las sociedades tiendan a censurarla con la risa. Atendamos a sus palabras: "Alli donde la materia logra condensar interiormente la vida del alma, fijar su movimiento, desterrar, en fin, la gracia, obtiene en seguida un efecto cómico. Si quisiéramos, pues, definir aquí lo cómico comparándolo con su contraste habría que oponerlo a la gracia a un mejor que a la belleza. Lo cómico es más bien rigidez que fealdad"10. He aquí, precisamente, una de las distancias más radicales de Bergson con la tradición moderna. Las definiciones clásicas que entienden la fealdad en tanto ausencia de gracia, como la fuente de la risa, quedan desbancadas ante este vitalismo optimista. No se trata pues de reducir el fenómeno de la risa a lo puramente estético. Se separa de aquellos thelos que, como el pensado por Fichte, tienden hacia el perfeccionamiento general a partir del arte, o inclusive del telos propugnado por Nietzsche en tanto disolución de lo apolíneo frente a lo dionisíaco. Si concedemos que la risa es un gesto-social, la "naturalidad" que implica la estética

Cf. Bergson, H., L’Evolution créatrice, París: Presses Universitaires de France, 1969.

9 Inmovilidad en sentido de posibilidad, ya que no existe fácticamente ningún elemento en dicho estado. De ahí que la risa nos salve de la rigidez con la tendencia que implicaría dicha inmovilidad al no-ser.

${ }^{10}$ Bergson, H., La risa: ensayo sobre la significación de lo cómico, p. 27. 
bergsoniana deslegitimiza a la risa como un tipo de arte y precisamente de ahí surge la resonancia en el ethos: "esta rigidez constituye lo cómico y la risa su castigo"11. Es este uno de los engranajes medulares del pensamiento bergsoniano en torno a la risa y su concreción narrativa (la comedia): ni lo uno ni lo otro participan del espectro estético.

Ahora bien, al binomio tensión-elasticidad se contrapone la categoría de lo "mecánico". Esta no solo regula los sistemas estructurales de lo cómico, sino que pone en marcha el ethos del telos de lo social. No es extraño, entonces, que para Bergson la categoría misma posea alcances ontológicos. Es decir, si existiera algo que pudiera contraponerse a la vida, sería precisamente lo mecánico. Ante la imagen de la organicidad, lo mecánico resulta lo sin-vida que por ello se vuelve risible: "No es ya la vida lo que tengo delante, es el automatismo instalado en la vida y probando a imitarla. Es lo cómico"12. Esta rémora, este parásito que intenta lo imposible (fijar el movimiento) no solo debe identificarse, sino incluso ser censurado por la risa. Este puro automatismo no es un automatismo puro ya que contiene implicitamente connotaciones y denotaciones de error ${ }^{13}$. Pensar en una naturaleza arreglada mecánicamente resulta no solo absurdo y grotesco, sino totalmente cómico. No pensamos agotar al lector con bastos ejemplos, porque de esto se ha encargado ya Bergson. Es suficiente mencionar que la cosificación de cualquier ser del ente en movimiento es risible. Una de las líneas del texto es sintomática en este sentido: "nos reímos siempre que una persona nos da la impresión de cosa"14.

\section{Lo cómico, lo mecánico y lo absurdo}

De esta forma hemos llegado a la disolución de la ambigüedad sobre lo cómico que, paradójicamente, según el autor, nos devuelve a un asunto nuevamente ambiguo. Lo cómico no pertenece por entero a la actividad artística ni a la vida ya que en el primer caso entran en juego las emociones y en el segundo la organicidad que, como hemos visto, difiere mucho de la mecanicidad en tanto fuente de lo cómico. Aboquémonos primero, atendiendo al propio filósofo, al análisis de la emoción. Si partimos de que la risa es una especie de broma que

11 Ibid., p. 23.

12 Ibid., p. 29.

13 Analécticamente a la noción de otro en la mayor parte del pensamiento post-hegeliano. Bástesenos recordar, a manera de ejemplo aleatorio, que el mismísimo Kierkegaard hace hincapié en el papel social al identificar el error en tanto pecado.

14 Bergson, H., La risa: ensayo sobre la significación de lo cómico, p. 44. 
nos tiende lo social para poner de relieve lo "mecánico", se vuelve necesaria la cancelación de cualquier emoción para que esta se dé. Recordemos que para Bergson el desdoblamiento de la realidad simple hacia el instinto y la inteligencia se da en la vida y, por lo tanto, en el preciso momento en que entra en juego una emoción ya estamos en el campo de lo artístico. De ahí, precisamente, que la captación de la mecanicidad sea incompatible con la vida en cuanto, para la risa, la condición precisamente necesaria y no necesariamente suficiente es la insensibilidad. Si encontramos algún vínculo vivencial con lo mecánico no accederemos a su comicidad. En sus palabras: "Es necesario que no me conmueva. He aquí la única condición realmente precisa, aunque no sea suficiente"15. En otras palabras, donde hay identificación emotiva no habrá comicidad.

Ahora bien, la comprensión de esta mecanicidad en términos de "rigidez" es posible en la medida en que, para Bergson, esta se entiende como una profunda distracción para con el entorno. Precisamente de ahí que la rigidez, el automatismo y, finalmente, la insociabilidad, sean para el autor de La risa semánticamente equivalentes. Aquel miembro de una comunidad que cancele tanto la escucha como la atención a su entorno y a "sí mismo" en tanto miembro de dicha comunidad, será un blanco fácil de la risa. Sin embargo, si quien observa y escucha a aquel que no observa y no escucha se conmueve y se deja llevar por cualquier tipo de emoción, no solo la situación no le parecerá cómica en modo alguno, sino, al contrario, le aparecerá ante los ojos bajo el sello del más franco dramatismo. El arte trabaja con este tipo de acercamientos emocionales. Se presupone una disposición: la autorización de ser sujeto a la conmoción. De ahí que para Bergson sea justamente aquello que nos hace posible identificarnos no solo con las emociones de los otros, sino, con mayor ahínco, con la "naturaleza” misma: “¿Cuál es el objeto del arte? Creo que si la realidad viniese a herir realmente nuestros sentidos y nuestra conciencia, si pudiésemos entrar en comunicación inmediata con las cosas y con nosotros mismos, el arte sería nulo, o más bien, todos seríamos artistas, porque nuestra alma vibraría entonces al unísono con la naturaleza"16.

El artista no solo llega a figurarse las cosas por sí mismas, sino que, al estar habituado a ellas, al ser su campo de acción, imagina que no necesita de aquella sacudida del alma en tanto reprimenda que otorga la risa. De ahí la solemnidad de la comunidad artística. De esta forma, para Bergson, "la elec-

15 Ibid., p. 97.
16
Ibid., p. 103.

ARETÉ Revista de Filosofía, vol. XXXI, N 1, 2019 / ISSN 1016-913X 
trización del alma, que constituye la pasión"17 no es ya una rectificación del camino equivocado, sino una visión directa de la comunidad que nos arroja al encuentro de emociones personales y universales. Es por ello que el acontecer cómico no puede de suyo pertenecer al campo del arte ni al de la vida: se encuentra, al contrario, en medio de ambas.

Ahora bien, si existe algo que ignore el arte, la organicidad y la vida misma es sin duda la vanidad. O, si se quiere, en palabras del autor, la "Hija de la vida social"18. Resulta evidente que el eje principal en torno al cual la vanidad gira no es sino un intento radical de fijación, un impulso mecánico que pretende, contra toda naturaleza, detener lo indetenible, detener el movimiento.

Pues bien, ante la rémora social que la vanidad supone, Bergson nos ofrece un antídoto: "Por eso se podría decir que el remedio específico de la vanidad es la risa y que el defecto esencialmente risible es la vanidad"19. Todos los integrantes de una comunidad buscarán, ya sea en la cotidianidad material o en la idealidad narrativa, este defecto. Para Bergson, lo buscamos aunque sea por el simple afán de reírnos. Un claro ejemplo del acontecer de la vanidad en lo social está delineado por el endurecimiento profesional. Al contar con un repertorio iconográfico lingüístico dado en la mayoría de los casos y poseer una lógica interna, las profesiones y los oficios tienden con facilidad a la rigidez. $\mathrm{Su}$ repertorio de signos y emblemas unitarios genera hábitos simbólicos y particularidades epistémicas que al ser activadas tienden a solidificarse. A esto nuestro autor le llama lo "cómico profesional".

Entramos de lleno al territorio de "lo solemne". Lo solemne que no es solo lo especializado, sino lo especializado que pretende resistirse al movimiento y al cambio. Estancamiento que, como hemos visto, la "vida misma" simplemente no tolera. Por ello, Bergson se resiste con tanta intensidad al binomio entre lo absurdo y lo risible, que sostienen las posturas logicistas de corte clásico negando con toda fuerza que lo absurdo sea causa de lo cómico y mucho menos que los contornos que lo esbozan estén trazados por la lógica del absurdo. Este, el absurdo, es más bien un efecto, nunca una causa. Las implicaciones de pensar el absurdo como un efecto de lo vano son evidentemente radicales: la vanidad en tanto ausencia de organicidad resulta la partera del absurdo.

17 Ibid., p. 108

18 Ibid., p. 117.

19 Ibid., p 118. 


\section{El ethos del "enigma"}

Es pertinente señalar que las reminiscencias de Materia y memoria ${ }^{20}$ respecto al absurdo son evidentes toda vez que la memoria parece siempre jugar un papel importantísimo en el interior del movimiento que conduce al perfeccionamiento de lo social ${ }^{21}$. Para Bergson, mientras que la importancia del saber recordar posiblemente regula los ejes de la frigidez, el saber olvidar es tierra fértil para que la vida se abra paso: "Estoy conforme en que el buen sentido consiste en saber recordar, pero más todavía en saber olvidar, es el esfuerzo de un espíritu que se adapta y se vuelve a adaptar incesantemente, variando de idea al cambiar de objeto" 22 . La clara contraposición entre la disposición hacia el olvido y la pretensión de estabilidad social es otro de los movimientos que la risa modela. No es pues una simple adaptación al medio -el social, en este caso- en términos darwinistas, sino más bien un fluir con la "vida" en términos vitalistas.

Otro modo de lo absurdo es la idea fija. Una idealidad epistemológica implícita que nos llevaría a pensar que las ideas no son modeladas a partir de las cosas, sino las cosas a partir de las ideas, es decir, se ve lo que se piensa y en sentido estricto se ve lo que se imagina: "El que se obstina acaba de ajustar las cosas a su idea, en vez de que acomodarla a las cosas"23. Pues bien, en este acontecer se conjunta la mecanicidad, el absurdo y la falta de organicidad: un personaje que sigue su idea obsesivamente es el carácter, es la personificación de lo solemne. Dicha obstinación sin duda refiere a la pretensión de imponer cualquier idea sobre el movimiento.

En resonancia directa con esta solemnidad traducida en absurdo, entran en juego el drama y la locura. Ni una ni otra pueden despertar la risa: son más bien enfermedades, condiciones deplorables que incitan a la piedad. Bergson deja abierto el espectro de las complejas relaciones binarias entre la normalidad y la locura, para así legitimar fenómenos cómico-narrativos como el representando por Don Quijote: "Si existe una locura risible, tendrá que ser una locura conciliable con la salud general del espíritu, una locura/normal"24. Algo similar ocurre con la introducción conceptual del "reposo" entendido como

${ }^{20}$ Cf. Deleuze, G., El bergsonismo, Madrid: Cátedra, 1987, p. 21.

${ }^{21}$ Cf. Bergson, H., Materia y memoria: ensayo sobre la relación del cuerpo con el espiritu, Madrid: Alianza Editorial, 1977, pp. 193-195.

22 Bergson, H., La risa: ensayo sobre la significación de lo cómico, p. 123.

23 Ibid., p. 124.

24 Ibid. 
rasgo básico para comprender un aspecto más del fenómeno de la risa tal como es abordado por nuestro autor. La pereza cumple con la demarcación antes trazada de mecanicidad: el "buen fluir" no solo en la vida sino, en sentido fuerte, con la vida, exige atención. En este sentido, las consecuencias prácticas de los esbozos éticos vitalistas en La risa podrian sumariarse como sigue: un ser en la historia en constante atención y una mueca crítica dispuesta a sonreír. De ahí el miedo generalizado a la burla social: ser blanco de la risa implica no solo cierta torpeza o distracción, sino pereza ontológica. Precisamente aquí el sabor amargo que el filósofo encuentra en ese halo de materialidad que la risa posee: "La risa, entonces, no será muy benévola, pues pagará el mal con el mal"25. El contorno del ethos de lo cómico está pues trazado: la risa es un mal que señala otro mal.

Si bien es cierto que para el autor analépticamente al sueño, la risa tiene un impulso hacia el reposo, el carácter negativo en tanto corrección a partir de la humillación es su movimiento principal. Como ser vivo, el humano simplemente no puede abandonar la tensión que le debe a la vida y, en este caso, a la vida social. La risa castigará los excesos de vanidad y respetará a los honestos. No obstante, la misma duración real en la continuidad exige ambigüedad legislativa: "En este sentido no puede ser la risa absolutamente justa, y repito que no puede ser tampoco buena. Su misión es la de intimidar humillando. No la cumpliría si la naturaleza, previendo este efecto, no hubiese dejado hasta en el mejor de los hombres un pequeño fondo de maldad, o cuando menos de malicia" 26 .

El espectro optimista de este último movimiento en La risa es sutilmente desahuciado a partir de la desarmonía y la extrañeza. Simplemente es extraño, muy extraño, que el hombre ría, y el analizar sus causas en la desarmonía resulta para Bergson una atenta invitación a futuros pensamientos. Pues bien, desde la plataforma ahora establecida resulta posible afirmar que entre la risa y el gusto existe una resonancia dado el carácter de extrañeza no solo en la risa misma, sino en sus principios detonantes, intrínsecos movimientos y consecuencias sociales. Subsumir el "fluir" del vitalismo bergsoniano a la afirmación "la expansión de lo cómico es ilimitada; porque nos gusta reír y todos los pretextos son buenos" 27 no solo resulta factible sino verosimil en un siglo convulsionado por mecanicidades y banalidades al por mayor. Nos reímos, a fin de cuentas. El autor de La risa sabe que solo una respuesta que asuma cabalmente la

25 Ibid., p. 129.

26 Ibid., p. 131.

27 Ibid., p. 136.

ARETÉ Revista de Filosofia, vol. XXXI, N 1, 2019 / ISSN 1016-913X 
categoría de enigma podrá al menos sugerir nuevas sendas del pensarnos en realidad: "Porque es extraño que el hombre ría y el método de explicación de que hablaba antes no esclarece este pequeño misterio". Sugerimos una lectura hipermoderna de la risa, no solo para no parcializarle, sino, estructuralmente, para no traicionar el afán realista del autor. La espuma de nueva cuenta se ha escapado de las manos del filósofo. Tan solo nos queda aire, sal o agua, una necesidad de comprender lo que se nos escurrió entre los dedos y el afán de reírnos de todo ello.

Recibido: 02/06/2017

Aceptado: 06/03/2018

\section{Bibliografia}

Bergson, H., La risa: ensayo sobre la significación de lo cómico, Madrid: Orbis, 1986.

Bergson, H., Materia y memoria, Madrid: Alianza Editorial, 1977.

Bergson, H., L’Evolution créatrice, París: Presses Universitaires de France, 1969.

Cherniavsky, A., "La risa como práctica formativa vitalista. La función y el valor de la risa en Spinoza, Nietzsche, Bergson y Deleuze", en: Configuraciones formativas II, 2, 2007.

Deleuze, G., El Bergsonismo, Madrid: Cátedra, 1996.

Yankelevitch, V., Henri Bergson, Xalapa: Universidad Veracruzana, 2006. 